\title{
Repair of postdissection descending thoracic aneurysm with right-sided aortic arch and aberrant left subclavian artery
}

\author{
Fabrizio Follis, MD, ${ }^{\mathrm{a}}$ Gianfranco Filippone, MD, ${ }^{\mathrm{a}}$ Giuseppe Montalbano, MD, ${ }^{\mathrm{a}}$ Ettore LoBianco, MD, ${ }^{\mathrm{b}}$ \\ Mario Finazzo, $\mathrm{MD},{ }^{\mathrm{c}}$ and Marco Follis, ${ }^{\mathrm{a}}$ Palermo, Italy
}

Right-sided aortic arch (RAA) with Kommerll's diverticulum and aberrant left subclavian artery (LSA) is a rare condition occurring in 0.05 of the population (Figure 1, $A$ ). In this group of patients, atherosclerotic aneurysms of the descending thoracic aorta are even less common and only a few cases have been described in the literature. Recently, we operated on a patient with RAA with aberrant LSA who had had a type $\mathrm{B}$ dissection in the past and was brought to us with aneurysmal dilatation of the descending aorta.

\section{CLINICAL SUMMARY}

A 68-year-old white man was admitted with chest pain of recent onset. Multislice computed tomographic aortography with tridimensional reconstruction revealed RAA with aberrant LSA, originating from a Kommerell's diverticulum, and an old type $\mathrm{B}$ aortic dissection with aneurysmal dilatation of $8 \mathrm{~cm}$ (Figure 1, $B$ ).

A right double thoracotomy in the fourth and seventh intercostal spaces was performed, and cardiopulmonary bypass was instituted through direct cannulation of the

$\overline{\text { From Department }}$ of Cardiac Surgery, ${ }^{\mathrm{a}}$ Anesthesiology, ${ }^{\mathrm{b}}$ and Radiology, ${ }^{\mathrm{c}}$ ARNAS, Palermo, Italy.

Disclosures: None.

Received for publication March 2, 2009; revisions received May 16, 2009; accepted for publication Aug 9, 2009; available ahead of print Nov 12, 2009.

Address for reprints: Fabrizio Follis, MD, piazza Castelnuovo 26 A, 90141, Palermo, Italy (E-mail: follis99@hotmail.com).

J Thorac Cardiovasc Surg 2010;139:1086-7

$0022-5223 / \$ 36.00$

Copyright (c) 2010 by The American Association for Thoracic Surgery

doi:10.1016/j.jtcvs.2009.08.032

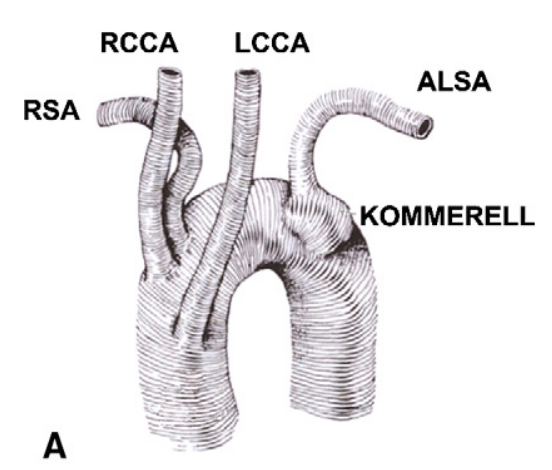

ascending aorta and right atrium. Repair was carried out with the patient under deep hypothermic circulatory arrest with retrograde cerebral perfusion with three Dacron grafts. The first $(22 \mathrm{~mm})$ was anastomosed to the distal arch and the second $(20 \mathrm{~mm})$ to the origin of the Kommerell's diverticulum on one side and to the first graft on the other end. Finally, the first graft was connected end to end to a third graft $(30 \mathrm{~mm})$ that had been anastomosed distally to the aorta immediately above the diaphragm, including both the true and false lumina (Figure 2, A).

The postoperative course required a temporary tracheostomy because of chronic obstructive pulmonary disease. He was discharged home in good condition, and computed tomography demonstrated good alignment of the three grafts (Figure 2, B).

\section{DISCUSSION}

Surgical treatment of atherosclerotic aneurysm in patients with RAA with aberrant LSA represents a formidable challenge for the cardiac surgeon. The addition of a postdissection anatomy further complicates the repair and requires a well-planned strategy. An accurate preoperative evaluation with multislice computed tomographic aortography is essential to define the relationship between the congenital anomaly and the acquired pathologic condition and to enable the surgeon to move with some familiarity in an anatomic field he or she probably is seeing for the first time.

A review of the cases reported, to decide the approach, perfusion strategies, and techniques of surgical reconstruction, is equally mandatory before undertaking the repair.

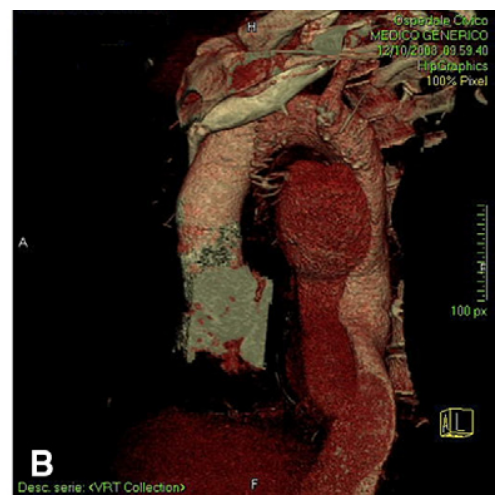

FIGURE 1. A, Line drawing of RAA with Kommerell's diverticulum and aberrant LSA. B, Three-dimensional image of aneurysm of false lumen. ALSA, Aberrant left subclavian artery; $L C C A$, left common carotid artery; RCCA, right common carotid artery; RSA, right suclavian artery. 


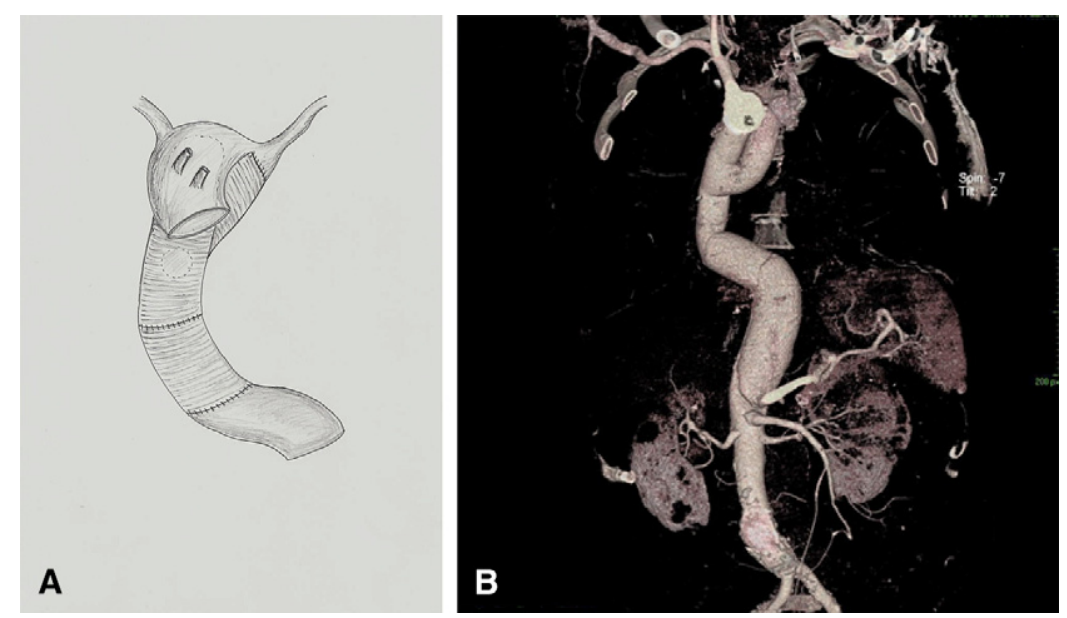

FIGURE 2. A, Line drawing of completed reconstruction. B, Three-dimensional image of repair.

The majority have been approached through a right lateral thoracotomy in the fourth intercostal space, which gives an excellent exposure for the repair and to the heart for institution of cardiopulmonary bypass. Alternatively, in the patients $^{1,2}$ in whom a median sternotomy incision was performed, it had to be extended with an additional right anterior thoracotomy. On the other hand, a bilateral thoracotomy carries the risk of additional morbidity.

In some cases, ${ }^{1-3}$ the repair has been carried out during deep hypothermic circulatory arrest with either antegrade or retrograde perfusion, whereas in others ${ }^{1,2}$ partial cardiopulmonary bypass, aortic crossclamping, and distal perfusion have been used. In our opinion, the choice between these two strategies has to do with the ease and ability to encircle and clamp the distal arch. Often, it is almost impossible, inasmuch as the Kommerell's diverticulum is intimately related to the posterior wall of the distal arch and a safe plane of dissection is difficult to establish.

Often two grafts are needed to complete the repair ${ }^{1,2,4}$ : one graft to revascularize the subclavian artery and exclude the Kommerell's diverticulum and another graft to re-establish continuity between distal arch and thoracic aorta below the aneurysm. This was also our experience: it is mandatory by the way the anatomy presents itself, once the aneurysm is opened, with two distinct lumina, the distal arch, and the mouth of the Kommerell's diverticulum, which cannot be included in one anastomosis. Otherwise, to simplify the proce- dure and use only one graft, a left carotid-LSA bypass, with proximal ligation of the subclavian artery, has been performed before thoracotomy. ${ }^{3}$ This option was discussed in our case but left aside in favor of a more "anatomic" reconstruction.

We elected to use a third graft to better match the discrepancy between the distal arch and the diaphragmatic aorta and make the distal anastomosis easier to perform in a confined field just at the level of the diaphragm.

Finally, a left carotid-LSA bypass followed by endovascular stent placement has also been proposed as an elegant and lower risk alternative. ${ }^{5}$ Unfortunately, this was not considered an option in our patient because of the presence of a true and false lumen, each one supplying different organs.

\section{References}

1. Tsukube T, Ataka K, Sakata M, Wakita N, Okita Y. Surgical treatment of an aneurysm in the right aortic arch with aberrant left subclavian artery. Ann Thorac Surg. 2001;71:1710-1.

2. Ota T, Okada K, Takanashi S, Yamamoto S, Okita Y. Surgical treatment for Kommerel's diverticulum. J Thorac Cardiovasc Surg. 2006;131:574-8.

3. Robinson BL, Nadolny EM, Entrup MH, Svensson LG. Management of right-sided aortic arch aneurysms. Ann Thorac Surg. 2001;72:1764-5.

4. Oberwalder PJ, Bergman P, Tillich M, Rigler B. Aneurysm of a right-sided aortic arch and right descending aorta: three-dimensional volume rendering of mulitislice computed tomographic aortography facilitates surgical planning and management. J Thorac Cardiovasc Surg. 2005;129:953-4.

5. Naoum JJ, Parenti JL, LeMaire SA, Coselli JS. Endovascular repair of a right sided descending thoracic aortic aneurysm with a right sided aortic arch and aberrant left subclavian artery. Ann Thorac Surg. 2008;85:1074-6. 